\title{
Indigenous African philosophy of Ubuntu as a foundation for a conducive environment for culturally responsive teaching and learning in South Africa
}

\author{
Dr Khazamula J. Maluleka
}

University of South Africa, College of Education, Department of Educational Foundations, Pretoria, South Africa

\begin{abstract}
:
One of the impacts of colonisation is the nullification of the indigenous African philosophies that would assist in laying the foundation for a culturally responsive environment for teaching and learning. The purpose of this research is to determine the way in which the indigenous African philosophy of Ubuntu can create a conducive environment for culturally responsive teaching and learning (CRTL). The qualitative research approach and action research methodology were used in this article. In addition, questionnaires (for academics) and interviews in the form of a talking circle (for indigenous elders) were used to collect data. The focus group sample, consisting of 5 academics and 10 indigenous elders of different ethnicities, were purposefully selected. Findings from the participants confirm the importance of the principles of Ubuntu for the creation of a conducive CRTL environment. This article concludes by accepting the importance of the indigenous African philosophy. It is therefore recommended that this philosophy be accommodated within the school environment to create a conducive environment for CRTL.
\end{abstract}

Keywords: African philosophy, culturally responsive, implicit curriculum, societal curriculum, Ubuntu 


\section{Introduction and problem postulation}

South Africa (SA) is one of the countries with the most dehumanising and destructive colonial pasts of any nation in Africa (Biraimah, 2016; Krakouer, 2015). Like other African countries, it is home to diverse cultural groups. The history of indigenous education in SA, like that of Australia, has been characterised by discrimination, marginalisation and limited access (Oliver \& Oliver, 2017:3). The successive colonial regimes of Britain and apartheid inflicted brutality on the culturally responsive education of indigenous people (Biraimah, 2016). The philosophy of Ubuntu that created a conducive environment for the transmission of indigenous knowledge was nullified and considered barbaric during the reign of the British and apartheid governments.

As indicated previously, the dehumanising and destructive colonialism by the British government was replaced by that of the apartheid government that took over after the second Anglo Boer war. Instead of including culturally responsive teaching and learning (CRTL), the apartheid regime went on to prioritise western cultures over African culture (Waghid, 2018:18). Apartheid literally means 'apartness' and was a system of government implemented in SA between 1948 and 1994 that separated education according to race. It entrenched the western education of the white minority and discriminated against the indigenous education systems of the non-white population groups. Although apartheid ended 25 years ago, recovery from its systematic racial discrimination is difficult to overcome and an ongoing process. Despite the challenge today, SA strives to leave behind its troubled past and harness the power of education to provide a culturally responsive curriculum that will bring equality and quality of life to all its citizens. The philosophy of Ubuntu, with its emphasis on cultural inclusiveness, equity and equality, is central to SA's pursuit of the goal of CRTL (Waghid, 2018:22). Significant challenges stand in its way, including a populace with multiple mother tongues and cultural traditions.

After a brief summary of SA's colonial past, the purpose of this research is to determine the way in which the indigenous African philosophy of Ubuntu can create a conducive environment for CRTL. Letseka (2013) alluded to the fact that "on a daily basis, homes, 
schools, work places and public spaces are bombarded by reports from the public media (the radio, television and print media) on violent crime, murder, rape, assault, police brutality and similar moral indiscretions". Currently, news about learners killing other learners, or learner killing teachers at secondary schools, are commonly reported. Recent news in SA included a student throwing a book at the teacher, and another student throwing water on the teacher's face (Msila, 2009). These cases are exacerbated by gangsters within schools. This creates a challenge for communities in establishing a conducive environment for teaching and learning.

The concept of Ubuntu, which one sees as an alternative to challenges, has been studied extensively in various disciplines (Msila, 2009; Letseka, 2012). Authors are in agreement regarding its significance, particularly in relation to its interdependent nature on collaboration, management and leadership (Biraimah, 2016; Msila, 2008; Sambala, Cooper \& Manderson, 2019). However, there is also a need to consider it as a foundation for a conducive CRTL environment. As long as people still experience violent crime, murder, rape, assault, bullying and gangsterism (Blackwood, 2018), more still needs to be done since these issues disturb conducive learning and teaching.

\section{Theoretical framework: constructivist theory}

The term 'constructivism' refers to the idea that learners construct knowledge for themselves as they perform activities (Krasnoff, 2016:2). Olusegun (2015) posits that learners learn by fitting new information together with what they already know and have learned at home in their social environment. What they have learned from home is related to culture (Narayan, Rodriguez \& Araujo, 2013:169). Understanding and interpreting new experiences thus depend on the knowledge learners have already acquired (Nyback, 2013:5). In addition, Mvududu (2019:1) believes that learning is affected by the context in which an idea is taught, as well as by learners' beliefs and attitudes. People cannot talk about what is learned separately from what is learned. The function of the content, the context, the activity of the learner, as well as the learner's goal must be well understood. The learning environment has some stimulus for learning and the social environment is critical to the development of knowledge. The 
knowledge learners bring to school is central to learning. To overlook prior experiences gained at home is to deny children access to the knowledge construction process.

Powell and Kalina (2009) maintain that there are two major types of constructivism in the classroom: cognitive or individual constructivism according on Piaget's theory, and social constructivism according on Vygotsky's theory. They further claim that even if these theories seem to be differing, they both emphasise that learners' creation of the concepts is built on existing knowledge. For this article, the social constructivism was preferred since the study deals with the inclusion of the African philosophy of Ubuntu which schools can adopt from society to create a conducive environment for teaching and learning.

Vygotsky (1978:57) argues that the social constructivist theory emphasises that human development is socially situated, and knowledge is constructed through interaction with others. Social constructivism is a highly effective theory of teaching that all learners can benefit from, since collaboration and social interaction are incorporated (Chaiklin, 2003). It emphasises the importance of culture and context in understanding what occurs in society, and constructs knowledge based on this understanding. Learning is thus considered to be a largely situation-specific and context-bound activity (Liu \& Matthews, 2005:387). The social constructivist theory explores reality and the influence of individual meaning based on life experiences, societal and cultural expectations, rules and norms.

\section{Literature Review}

According to constructivists, education is an epistemological perspective of learning focused on how learners actively create knowledge out of their experience. The knowledge creation process needs a conducive environment to ensure that teaching and learning respond to the culture of the learners being taught. This section intends to demonstrate the ways in which the African philosophy of Ubuntu can lead to CRTL.

\subsection{Culturally responsive teaching and learning (CRTL)}


CRTL is the use of cultural knowledge and prior experiences to make teaching and learning relevant and effective (Gunn, 2018). CRTL acknowledges the value of different ethnic groups' cultures (Misco, 2018:84). It brings home and school together. Krasnoff (2016:2) presents socio-cultural consciousness, attitude, commitment and constructivist views as characteristics that would prepare teachers to be culturally responsive. He cites constructivist views as being among the characteristics of culturally responsive teaching. The constructivist perspective considers learning as a process by which learners generate meaning in response to new ideas and experiences they encounter in school.

\subsection{African philosophy of Ubuntu}

The definition of 'African philosophy' has remained a recurring problem and there is little agreement as to what it is (Oyeshile, 2008). Oyeshile (2008) further maintains that most philosophers settled for the description of African philosophy rather than defining it. 'African philosophy' is defined by Janz (2009) as a viewpoint produced by African people which portrays Africans' perceptions of the world in which they live. Akinpelu (1981) defines it as the application of principles of philosophy to solve problems of education in Africa. It can be defined as critical thinking by Africans on their experiences of reality. It is the work of philosophers of African descent. An African philosophy of education is a way of asking questions about education in Africa. In this article, the African philosophy of education is taken to mean an integrated thought process that examines educational issues from African perspectives in accordance with universal thinking, to arrive at solutions that make education relevant and meaningful to Africa.

Ubuntu is one of the examples of African philosophy. Letseka (2012:54) considers Ubuntu as a communitarian philosophy that emphasises features such as compassion, tolerance and harmony. Ubuntu is found in diverse forms and languages in many societies throughout Africa (Murithi, 2006).

- In Shona (Zimbabwe), the term is Unhu (Hapanyengwi-Chemhuru \& Makuvaza, 2014:1);

- in Malawi (Chichewa and Tumbuka), it is called uMunthu; 
- in Kenya and Tanzanian (Kiswahili), it is $u t u$;

- in the Democratic Republic of Congo, it is called bomoto; and

- in Mozambique, in XiTsonga, it is referred to as vumunhu (Sambala, et al. 2019:5).

In southern Africa, the traditional understanding that one is truly human only as a member of a community is expressed in terms of Ubuntu. It is, at the same time, the foundation of African philosophy.

\subsection{Values of African philosophy of Ubuntu}

According to the constructivist theory, individuals construct new knowledge from their experiences. The construction of such knowledge depends on the environment in which learning takes place. If the environment is not conducive, knowledge construction will be just a dream that cannot be realised. For the environment to be conducive, the schools have to take the values, such as Ubuntu-inspired leadership, creating peace, discipline, respect, care, empathy/compassion, morality, ethics, honesty, hospitality, sharing and tolerance, into consideration. Efforts at reviving the notion of Ubuntu is necessary for the above-mention values (Matolino \& Kwindingwi, 2013:197). The next section discusses these values.

One of the pillars of Ubuntu is good leadership that will see schools run in a proper manner. Setlhodi (2019:130) argues that Ubuntu-inspired leadership is an African construct that could improve learners' performance. In addition, Msila (2008:70) maintains that principals need to have the best leadership style to help them manage their institutions in a meaningful way. Letseka (2012) also agrees that academically superior schools are those that are currently embracing Ubuntu leadership. According to Setlhodi (2019:132), some of the best leadership styles include letsema (voluntary services) and lekgotla or imbizo (phrases meaning people's assembly), which must be considered to improve community engagement.

In addition to providing leadership that is Ubuntu-inspired, creating peace within schools would lead to a conducive CRTL environment. In SA, reference is always made to Ubuntu for communities living in harmony and interdependence (Letseka, 2012). The focus of the 
schools should be on creating peace within the institution for conducive learning, with the emphasis on fostering peace using Ubuntu. Ubuntu can be regarded as the key to a good character towards others (Msila, 2009). Mbiti (1971) provides the Zulu phrase "Umuntu ngumuntu ngabantu", which means a human being is a human being because of other human beings.

The creation of peace relies on the discipline of the members of the communities. According to Letseka (2011), the philosophy of Ubuntu is reflected by the school discipline. Taking Ubuntu into consideration will make the teaching and learning environment conducive. Msila (2008) argues that ill-disciplined learners show a failure to embrace the principles of Ubuntu. This absence of Ubuntu would result in undesirable outcomes in schools. Letseka (2011) maintains that the school staff should respect and care for themselves and learners in the school, irrespective of their background or circumstances. Msila (2008) agrees that when schools embrace Ubuntu, people will observe a disciplined student body. Respect, as postulated by Ubuntu, must be inculcated in learners to create a conducive environment for teaching and learning in schools. All these authors agree on the importance of Ubuntu in moulding the behaviour of learners.

Peace, discipline and respect rely on the moral behaviour of the community members. Like members of the community, learners have to be ethical, honest, and honourable. Ubuntu, as an African philosophy, is embedded in the moral values of African communities (Chisale, 2018:3). Letseka (2012:54) did not only consider Ubuntu as a philosophy, but went further to regard it as a moral theory. In addition, Teffo (1994) argues that Ubuntu serves as a unifying moral value in the face of harsh conditions. Young people who are initiated into Ubuntumorality have the potential to become citizens that are inclined to treat others with justice and fairness at all times. Teffo (1994) argues that the culture of Ubuntu is the "capacity to express compassion, justice, reciprocity, dignity, harmony and humanity in the interests of building, maintaining and strengthening the community". Ubuntu expresses the community interconnectedness, their common humanity and the responsibility to each that flows from their connections. 
The moral behaviour of the indigenous communities was not only applied to its members. To display their hospitality, the Ubuntu philosophy embraced the positive attitude of welcoming travellers, strangers and any visitors. Chisale (2018:5) posits that the hospitality was reflected in the Nguni saying "isisu somhambi asingani singangenso yenyoni” " [a traveller's stomach is as small as a bird's kidney]. Travellers among the indigenous people were welcomed and given the cooling drink called amahewu [fermented soft porridge] and a place to rest until they were ready to continue their journey (Chisale, 2018:5). He further maintains that the traditional Nguni saying "Siyakwamukela" or "wamlekile ekhaya" [you are welcome] showed a traveller that she or he was valued and respected.

For years, indigenous people have been displaying the attitude of caring and sharing for others. Their needs become your needs. Their joys and sorrows become your joys and sorrows. It is the practice of concern and oneness. The African saying "izandla ziyagezana" [hands wash each other], means helping each other in how to execute care (Chisale, 2018: 3). Kehoe (2019) maintains that Ubuntu teaches people that "we are human through our interaction with others. Without others, we are not human". African traditional values and notions about caring for others have been affected as a result of changes that came due to capitalism, inequality, poverty, joblessness and broken families (Sambala, et al. 2019:9). The surplus that African's used to share is now used for profit-making. Inequality, poverty, unemployment and broken families resulted in disturbances that led to social ills which affected the harmony that used to prevail within the African societies. These circumstances also affected the harmonious social order expected in schools. For Sambala, et al. (2019:9), the solution to these social challenges can be found within the philosophy of Ubuntu.

Empathy and compassion are also pillars of Ubuntu that cannot be left out in creating a school environment that is conducive for smooth teaching and learning. Empathy is the ability to successfully enter into the emotional situation of another, to listen and feel genuine sympathy because you hear and feel what others share with you. You listen with your mind, but you also feel with your body, and this feeling allows you to 'see' the situation from a deeper 
perspective. When we cultivate the practice of empathy, it deepens us and gives us access to more humanness with which we can help others.

\section{$4 \quad$ Research design}

This is a qualitative study, intending to determine the way in which the indigenous African philosophy of Ubuntu can lay a foundation for a conducive environment for CRTL. Social constructivism, the theory that underpins this study, emphasises the importance of culture and context in which the African philosophy of Ubuntu manifests (Chaiklin, 2003). To be able to take the culture and context of the community into consideration, the researcher used participatory action research. Action research is an approach whereby the researcher and a participant collaborate in the diagnosis of the problem and in the development of a solution. According to Chilisa (2012:227), participatory action research consists of a cycle of steps. For this article, the following steps were used to collect data:

\section{Step 1: Plan - Considering alternative courses of action}

The planning stage included identifying and inviting the community members to be part of the research (Chilisa, 2012:227). The purposeful sampling technique was used to select people who took part in this research. The sample consisted of 5 academics who have written extensively on the African philosophy of Ubuntu and CRTL. In addition to the academics, 10 10 indigenous elders, divided into two groups, became part of the participants. These groups consisted of males and females of various ethnic groups, including Nguni (Isizulu/Xhosa), Sotho-related languages (Setswana, Northern and Southern Sotho), Xitsonga and Xi-venda, and Shona-speaking people originating from Zimbabwe and presently reciting in SA.

The following questions were used to collect data to answer the research question:

\begin{tabular}{|l|l|}
\hline Questions for academics: & Questions for Indigenous elders: \\
\hline - What is your understanding of the & $\bullet$ Literature indicated that the Zulu- \\
concepts 'indigenous African & $\begin{array}{c}\text { speaking people use the concept } \\
\text { 'Ubuntu'. Which concept or word do you }\end{array}$ \\
\hline
\end{tabular}




\begin{tabular}{|l|l|}
\hline $\begin{array}{l}\text { philosophy', 'Ubuntu' and 'culturally } \\
\text { responsive teaching'? }\end{array}$ & use in your own culture/languagelethnic \\
- How did Ubuntu contribute to the & group? \\
transmission of knowledge within the & • What is the meaning of the concept \\
communities? & 'Ubuntu' in your own culture? \\
- How can Ubuntu create a conducive & \\
$\begin{array}{l}\text { environment for teaching and learning } \\
\text { in schools? }\end{array}$ & - Explain the importance of Ubuntu in your \\
- How did indigenous people use Ubuntu & of indigenous knowledge system. \\
to provide quality leadership that made & \\
the transmission of indigenous & How would Ubuntu contribute in bringing \\
knowledge possible? & discipline in schools? \\
How did indigenous people use Ubuntu & \\
to maintain discipline to create a & \\
conducive environment for knowledge &
\end{tabular}

Step 2: The plan of action put into place

Chilisa (2012:227) maintains that this is the stage in which the plan is put into action. Since the interviews and the observations were based on focus groups, actions took the form of talking circles (Chilisa, 2012:23). A focus group was preferred in this study since it is a socially orientated process to generate data that will assist in determining the way in which the indigenous African philosophy of Ubuntu can create a conducive environment for CRTL. As indicated in Step 1, the sample consisted of five academics and 10 indigenous elders. The indigenous elders were divided into two focus group consisting of five individuals each who shared certain characteristics relevant to the philosophy of Ubuntu. During focus groups, the researcher created a supportive environment in which discussion and differing points of view were encouraged. MacDonald (2012:35) advocates that concepts to be used during the interviews must be made clear to people who are supposed to provide answers. Through 
collaboration between the researcher and the participants, the indigenous African philosophy of Ubuntu and CRTL were made clear to the focus groups. The researcher prepared some tentative questions to be used prior to the focus groups. Participants answered those questions and added others they saw as relevant to the topic.

\section{Step 3: Participant observation}

Participant observation entails the systematic noting and recording of events, behaviours, and objects in the social setting through the use of detailed and comprehensive field notes. The observation was conducted after the interviews. Observation was not restricted to the people who participated in the interview and it was not formal. It was just observing people of different ethnic groups leading their normal daily life. Observations were done with all ethnic groups, and the process lasted five weeks. The intention was to verify the information participants provided during the interviews. An observation schedule, consisting of the Ubuntu values shared across cultures, was used. These values include care, compassion, community engagement, discipline, empathy, honesty, hospitality, leadership (lekgotla/imbizo), respect, sharing and tolerance (Blackwood, 2018).

The researcher was able to capture the context of the social setting in which participants function by recording subjective and objective human behaviour. The researcher also became part of the process being observed and was immersed in the setting, hearing, seeing, and experiencing the reality of the social situation with the participants. Thus, as a participantobserver, the researcher not only observed activities, participants, and physical aspects of the situation, but also engaged in activities appropriate to the social situation.

\section{Step 4: Reflect}

A self-reflection was conducted to check what all participants learned and contributed through the exercise. Chilisa (2012:227) states that reflecting on processes and consequences may lead to re-planning and observing again (if the expected results are not met). 


\section{$5 \quad$ Findings and discussion}

\subsection{Finding from the interviews}

The findings are based on themes that emerged from the collected data. The themes include the concepts indigenous African philosophy, Ubuntu, culturally responsive teaching; Ubuntu in various cultures; importance of Ubuntu in communities (discipline, social order, morals); contribution of Ubuntu in shaping behaviour in schools; improving school leadership; and creating a conducive environment for knowledge transmission within the community Ubuntu.

Theme 1: Indigenous African Philosophy, Ubuntu and culturally responsive teaching The meaning of indigenous African philosophy, Ubuntu, and culturally responsive teaching was provided by academic participants. In explaining the concept African philosophy, the participants provided the following remarks:

"African philosophy is the ethical idea produced by indigenous Africans people"

"A way of doing from an African perspective"

"It is a statement that identifies and clarifies the beliefs, values and understandings of an individual or group of people."

African philosophy is considered as communication or debate produced by indigenous African people. It is considered as a way of doing, from an African perspective. African philosophy is said to be based on norms, beliefs and values. Introducing African philosophy in education will add indigenous perspective, norms, beliefs and values to the learning experience.

In explaining the concept of Ubuntu, the participants provided the following remarks:

"Ubuntu is a humanist philosophy focusing on people's relations with each other." 


\section{International Conference on}

New Trends in Teaching and Education

"The word Ubuntu originate from the African languages and it is seen as an African concept."

"Many African countries have the concept Ubuntu in their own language ..."

“... view Ubuntu as something that provide us with values and principles to lead a peaceful life with others"

"It is a practice by indigenous people of Africa that ensures harmony within communities. It depict our humanness and the value of the community."

Ubuntu is considered to be a humanist philosophy guiding the relationship between members of the community. It is said to be an African concept which provides the principles that guide the harmonious practices of the indigenous people of Africa. It forges unity within the communities.

The participants' explanations of culturally responsive teaching include the following remarks:

"... it is teaching that display culture of the people taught ... a teaching that respond positively to a multicultural environment ..."

"Culturally responsive teaching is a teaching that appreciate the relevancy of culture in the classroom ... the importance of including cultural in teaching."

"Culturally responsive teaching is an educational activity that puts culture of learners at the centre of each learning process."

"Culturally responsive teaching is an activity in which teachers show their ability of incorporating culture in their teaching of a multicultural class ..."

CRTL is regarded as the transmission of knowledge that respects the culture of the learners being taught. It is teaching that responds to a multicultural classroom, which seems to be the character of the current situation in all schools.

Theme 2: Ubuntu in various cultures 
Literature has shown that various ethnic groups have Ubuntu in their languages. The responses from various culture/language/ethnic groups confirmed this idea:

“... as Nguni people we use the word Ubuntu to indicate that 'umuntu ngumuntu ngabantu' (a person is a person through other persons)"

“... the Setswana, Northern and Southern Sotho we commonly use the word Botho meaning 'motho ke motho ka batho' (a person is a person through other persons)"

“... Vatsonga use the word vumunhu which means mhunu i munhu hi van'wana”

“... as Venda speaking people we use the word Vhuthu which means muthu ndi muthu nga vhathu ..." (a person is a person through other persons)

"Shona people used the Unhu which means kunzi munhu vanhu ..."

This indicates that all African cultures have their own word that is related to Ubuntu. The meaning of the concepts from various cultures/languages are closely related. The concepts provided by various participants are Ubuntu, Botho, Vumunhu, Vhuthu, Unhu, all meaning that a person is a person through other persons. These concepts put more quality on human relations; unity within the family and the community; generosity, hospitality, friendliness, care and compassion to others.

\section{Theme 3: Values of Ubuntu}

Literature provides values of Ubuntu that serve as a foundation for the transmission of knowledge within the community. To confirm the contribution of Ubuntu, participants responded in the following manner:

“... we have been living in groups called clans. Ubuntu (botho) has been a unifying factor among these clans"

“... one important character of our people was sharing ... If one family had a good harvest will share the product with those did not produce sufficient food for themselves" 
“... through letsema (voluntary community work) and imbizo (people's assembly), we showed cooperation in performing the community work like seeing to it that our villages are well kept. This was not the responsibility of the municipality as it is taking place currently"

“Ubuntu made indigenous people to have hospitality as well as being friendly to visitors. Ubuntu governed our human relations. Those who did not have this character of Ubuntu were always unruly and uncontrollable. There were also ways of disciplining such people."

According to the above remarks, the way the clans were run indicate that indigenous leaders had their own style of leading which was characterised by letsema and imbizo. Both of these leadership styles are based on Ubuntu philosophy. Participants considered this philosophy as a unifying factor among ethnic groups; something that encouraged sharing and cooperation in performing the community work. Ubuntu gave indigenous people a character that is different from other societies. Being welcoming, hospitable and friendly are issues that were part of the indigenous way of living.

Theme 4: Contribution of Ubuntu in shaping behaviour in schools

From the literature, it is established that Ubuntu can create a conducive environment for teaching and learning. Some writers are convinced that Ubuntu can still bring changes in schools that are currently characterised by violence. In response to the question of the importance of Ubuntu in school, participants responded in the following manner:

“... Including Ubuntu into the education system will bring to an end killings that various countries experience in schools; ... as indigenous people we led our lives in harmony due to Ubuntu."

"If it becomes part of education, the character of harmony will be inculcated into the life of learners. Schools are experiencing bullying, fights and gangsters."

"Misbehaviour in schools shows that Ubuntu is missing." 
"Things have changed. The character of Ubuntu is no longer there within communities.

What is happening in the community currently shows that Ubuntu is no longer the unifying factor."

"What is taking place in the communities has been transferred to schools. Including Ubuntu in school curriculum will bring back good character that people use to enjoy."

Participants cited that Ubuntu will assist in bringing an end to the killings, bullying, fights, and gangsterism taking place in various schools. Including Ubuntu in school environments will create harmony in schools. As a unifying factor, Ubuntu will lead to a harmonious, human, generous, friendly, caring and sympathetic student body.

\section{Theme 5: Improving school leadership}

Literature indicates that indigenous people used Ubuntu to provide quality leadership that made the transmission of their knowledge possible. To add to the literature, the participants responded in the following manner:

“... our African leaders were not educated but had the best leadership style that kept the community as a unit ... letsema and makgotla/imbizo were some of the leadership styles used to get everybody involved in the improvement of the community life"

“... the respect that was levelled to African traditional leaders kept the clan together"

“... embracing Ubuntu leadership style by our great African leaders can still be used by any group of people who want to run their management effectively"

“... the same leadership style that was used by indigenous leaders to bring unity among their members can still be of value to schools"

From the above quotations, one realises that traditional leaders had an art of leading (letsema, makgotla/imbizo) that was highly respected. Leadership, which always involved the kings and their chieftaincies, made sure that rules are respected. This was possible because during the imbizos, kings and chieftaincies made people buy into the rules by contributing to its 


\section{International Conference on}

New Trends in Teaching and Education

formulation. Disciplining measures were council matters and endorsed by the traditional leader.

Theme 6: creating a conducive environment for knowledge transmission within the community - Ubuntu

Literature revealed that indigenous people use Ubuntu to maintain discipline, social order and morals to create a conducive environment for knowledge transmission. The following are some remarks by the participants:

“... discipline within the community was not only the responsibility of the traditional leaders alone ... a traditional council also contributed and all actions were governed by

Ubuntu."

“... misbehaviour by members of the community was an embarrassment to the whole community ... misbehaviour was viewed by every member of the community as a break of the social order"

"... there was no compromise to the norms of the community... revolting against the morals of the community could result to a fine or banishment from the community as the form of punishment"

These remarks indicate that indigenous people had their own way of keeping order. What should be appreciated is the fact that whatever rule was formulated was not presented in a topdown manner, since the community also participated in its formulation. There was an agreement within the community on how to keep the discipline within the members of the community. Measures of discipline did not come as a surprise to them.

\subsection{Finding from the observation.}

According to what was observed, all the values of Ubuntu are still practiced but to a lesser extent. For example, caring and sharing have been affected by a change to economic activities 
that used to rely on agricultural products and currently everything is about money. However, people still afford to share things like sugar, mieliemeal, pots and dishes, etc. The adoption of the western way of living pushed Ubuntu values to the background. Honesty, hospitality, respect, tolerance, discipline are no longer serving as the guiding force to the daily activities of the communities. Valuable activities such as Makgotla/imbizos (people's assemblies) and matsema (voluntary work within the communities that use to bring people together have been replaced by municipality work which is unable to bring service.

\section{Conclusion and recommendations}

The intention of this article was to determine the way in which the indigenous African philosophy of Ubuntu can serve as a foundation for a conducive CRTL environment. The study showed that an Ubuntu worldview can have a positive impact when its principles are infused into school. Introducing Ubuntu into the curriculum adds an indigenous character to education and can change the behaviour of unruly learners. Indeed, the inclusion of Ubuntu in the curriculum can be Africa's unique contribution. Honouring Ubuntu can make the world a more peaceful place. For this to happen, emphasis should be placed on the teaching of respect, decency and tolerance, as emphasised in the philosophy of Ubuntu. The question that remains unanswered is "how can the philosophy of Ubuntu be introduced into the curriculum to add an indigenous character into education?" The following recommendations attempt to provide an answer.

Letsema: Oneness, embodied by Ubuntu and voluntarism (letsema) of will, remain important as long as human beings exist. Through letsema (voluntary community work), indigenous people showed cooperation in performing community work, like seeing to it that their villages are well kept. Conducting letsema within the school community will ensure that everybody, especially the parents, are involved in school activities. Parents' involvement will introduce learners to the sense of voluntarism and working together as a group. Working together within the schoolyard will show that they need each other. This will reduce gangsterism in schools. 
Lekgotla/imbizo: African leaders were not educated but had the best leadership style that kept the community as a family. Lekgotla/imbizo is one of the leadership styles as a platform for sharing and contributing ideas. This can be used to get everybody involved in the improvement of the school. Embracing lekgotla/imbizo (people' assembly) will ensure that all stakeholders take part in the formulation of the rules used by the school's management team to run the schools effectively. Through people' assembly, all stakeholders, including learners, will be able to participate in decision making. Learners will understand the consequences of their actions. The Ubuntu leadership style can still be used by any group of people who want to run their management effectively. The same leadership style that was used by indigenous leaders to bring unity among their members can still be of value to schools.

Unifying factor: Ubuntu can be a unifying factor within schools. Infusing it in the curriculum will inculcate that character of sharing and working together. Schools are experiencing bullying, fights, and gangs because learners do not have a character of sharing. They cannot share a schoolyard; this shows that Ubuntu is missing.

Discipline within the community was not only the responsibility of the traditional leaders alone; a traditional council also contributed and all actions were governed by Ubuntu. The responsibility of the school's management cannot remain in the hands of the principal. Discipline within the school should be the responsibility of all stakeholders, including the leaners. There should be no compromise to the norms of the school. Revolting against the morals of the school should not be allowed by any stakeholders. Learners will buy into the norms of the school if they become part of formulating such norms.

Including Ubuntu into the education system will reduce or bring an end to the killings that various countries are experiencing in schools. As indigenous communities lead their lives in harmony due to Ubuntu, schools can follow suit. If it becomes part of education, the character of harmony will be inculcated into the life of learners. What is taking place in the communities has been transferred to schools. Including Ubuntu in the school curriculum will bring back the good character that communities used to enjoy. Harmony, humanness, generosity, hospitality, 
friendliness, care and compassion are some of the aspects of Ubuntu that are meant to be taken to our schools.

CRTL is the use of cultural knowledge and prior experiences to make teaching and learning relevant and effective. CRTL acknowledges the value of different ethnic groups' cultures. It brings home and school together. The best way to make teaching and learning respond to culture, is for teachers to use examples from the learner background.

Social constructivism is a highly effective theory of teaching that all learners can benefit from, since collaboration and social interaction are incorporated. It emphasises the importance of culture and context in understanding what occurs in society and constructing knowledge based on this understanding. Whatever programme is planned for teaching and learning in classrooms must take note of what is happening within society, and teachers and learners are part of society.

Implicit and societal curricula can assist to infuse Ubuntu philosophy into schools. Implicit (or hidden or covert) curricula is the kinds of learning children derive from the behaviours and attitudes of teachers and administrators. The teacher should consciously expose learners to values and norms. The societal curriculum (or social curricula), on the other hand, is an ongoing, informal curriculum of family, peer groups, neighbourhoods, churches, occupations, and other socialising forces that educate all of us throughout our lives. The hidden curriculum is the transmission of norms, values, and beliefs conveyed in the classroom and the social environment. There is room for Ubuntu in implicit and the societal curricula. The indigenous teachers bring principles of Ubuntu with them, which they can consciously or unconsciously expose student to. 


\section{Reference}

- Akinpelu, J.A. (1981). An Introduction to Philosophy of Education. London: Macmillan.

- Biraimah, K.L. (2016). Moving beyond a destructive past to a decolonised and inclusive future: The role of Ubuntu-style education in providing culturally relevant pedagogy for Namibia. International Review of Education, vol. 62, pp. 45-62. DOI: 10.1007/s11159016-9541-1.

- Blackwood, A. (2018). A Review of 'You Can't Teach Us If You Don't Know Us and Care About Us: Becoming an Ubuntu, Responsive and Responsible Urban Teacher'. Multicultural Perspectives, 20(4), pp. 257-260, DOI: 10.1080/15210960.2018.1467768. https://doi.org/10.1080/15210960.2018.1467768

- Chaiklin, S. (2003). The zone of proximal development in Vygotsky's analysis of learning and Instruction. In Kozulin, A., Gindis, B., Ageyev, V. and Miller, S. (2003). Vygotsky's educational theory and practice in cultural context. Cambridge: Cambridge University Press.

- Chilisa, B. (2012). Indigenous Research Methodologies. SAGE Publishers, Inc. United Kingdom: London

- Chisale, S.S. (2018). 'Ubuntu as care: Deconstructing the gendered Ubuntu'. Verbum et Ecclesia, 39(1), a1790. https://doi.org/10.4102/ ve.v39i1.1790.

- Gunn, J. (2018). Understanding Culturally Responsive Teaching. [28 June 2019] https://education.cu-portland.edu/blog/leaders-link/culturally-responsive-teachingstrategies/.

- Janz, B.B. (2009). Philosophy in an African Place. Rowman \& Littlefield Publishers, Inc. UK: Plymouth. 
- Hapanyengwi-Chemhuru, O. and Makuvaza, N. (2014). Hunhu: In Search of an Indigenous Philosophy for the Zimbabwean Education System. Practice without thought is blind: thought without practice is empty. The Journal of Indigenous Social Development, 3(1), pp. $1-15$.

- Kehoe, J. (2019). Mind Power: Ubuntu (African Wisdom) Part II [07 April 2019] https://www.learnmindpower.com/article/ubuntu-african-wisdom-how-be-human-beingpart2/

- Krakouer, J. (2015). Literature review relating to the current context and discourse on Indigenous cultural awareness in the teaching space: Critical pedagogies and improving Indigenous learning outcomes through cultural responsiveness. Australian Council for Educational Research.

- Krasnoff, B. (2016). Culturally Responsive Teaching: A Guide to Evidence-Based Practices for Teaching All Learners equitably. Region X Equity Assistance Center. Education Northwest http://educationnorthwest.org/equity-assistance-center/

- Letseka, M. (2012). In Defence of Ubuntu. An International Journal Studies in Philosophy and Education, 31(1), pp. 47-60. DOI: 10.1007/s11217-011-9267-2.

- Letseka, M. (2013). Educating for Ubuntu/Botho: Lessons from Basotho Indigenous Education. Open Journal of Philosophy, 3(2), pp. 337-344 DOI:10.4236/ojpp.2013.32051

- Liu C.H. and Matthews, R. (2005). Vygotsky's philosophy: Constructivism and its criticisms examined International Education Journal, 6(3), pp. 386-399. http://iej.cjb.net.

- MacDonald, C. (2012). Understanding Participatory Action Research: A Qualitative Research Methodology Option, Canadian Journal of Action Research, 13(2), pp. 34-50 
- Matolino, B. and Kwindingwi, W. (2013). The end of Ubuntu. South African Journal of Philosophy, 32(2), pp. 197-205. DOI: 10.1080/02580136.2013.817637.

- Mbiti, J.S. (1971). African traditional religions and philosophy. New York: Doubleday.

- Misco, T. (2018). Culturally Responsive Curriculum and Pedagogy in the Commonwealth of the Northern Mariana Islands, International Journal of Multicultural Education, 20(2), pp. 81-100.

- Msila, V. (2008). Ubuntu and school leadership. Journal of Education, 44, pp. 67-84.

- Msila, V. (2009). Ubuntu and Peace-making in Schools. International Journal of Educational Policies, 3(1), pp. 51-66.

- Murithi, T. (2006). African Approaches to Building Peace and Social Solidarity, African Journal on Conflict Resolution, 6(2), pp. 9-34.

- Mvududu, N. (2019). Culturally Responsive Teaching: The Bible Tells Me So. International Christian Community of Teacher Educators Journal, 14(1), pp. 1-9.

- Narayan, R., Rodiguez, C. and Araujo, J. (2013). Constructivism/Constructivist learning theory. In B. Irby, G. Brown, R. Lara-Alecio, and S. Jackson (Eds.), The handbook of educational theories (pp. 169-184). Charlotte, NC: Information Age Publishers.

- Nyback, M.H. (2013). A constructivist approach to teaching and learning at the degree programme in nursing at Novia University of Applied Sciences. (Report). Novia University, Finland.

- Oliver, E. and Oliver, W.H. (2017). The Colonisation of South Africa: A unique case. HTS Teologiese Studies/ Theological Studies, 73(3), a4498. https://doi.org/ 10.4102/hts.v73i3.4498 


\section{International Conference on}

New Trends in Teaching and Education

5-7 September, 2019

Barcelona, Spain

- Olusegun, B.S. (2015). Constructivism Learning Theory: A Paradigm for Teaching and Learning. IOSR Journal of Research \& Method in Education (IOSR-JRME), 5(6), pp. 6670.

- Oyeshile, O.A. (2008). On Defining African Philosophy: History, Challenges and Perspectives. Humanity \& Social Sciences Journal, 3(1), pp. 57-64.

- Powell, K.C. and Kalina, C.J. (2009). Cognitive and social constructivism: Developing tools for an effective classroom. Education, 130(2), pp. 241-250.

- Sambala, E.Z., Cooper S. and Manderson, L. (2019). Ubuntu as a Framework for Ethical Decision Making in Africa: Responding to Epidemics, Ethics \& Behavior, DOI: $10.1080 / 10508422.2019 .1583565$.

- Setlhodi, I.I. (2019). Ubuntu Leadership: An African Panacea for Improving School Performance. Africa Education Review, 16(2), pp.126-142. DOI: $10.1080 / 18146627.2018 .1464885$.

- Teffo, L.J. (1994). The concept of Ubuntu as a cohesive moral value. Pretoria: Ubuntu School of Philosophy.

- Vygotsky, L.S. (1978). Mind in Society. Cambridge: Harvard University Press.

- Waghid, Y. (2018). Ubuntu Caring: Cultivating Moral, Compassionate, and Restorative Justice in University Education towards a Philosophy of Caring in Higher Education, pp 89-96. 